\title{
Symptomatology, Pathophysiology, Diagnostic Work-up, and Treatment of Hirschsprung Disease in Infancy and Childhood
}

\author{
Fleur de Lorijn, $M D, P h D$, Guy E. Boeckxstaens, $M D$, PhD, \\ and Marc A. Benninga, MD, PhD
}

\author{
Corresponding author \\ Marc A. Benninga, MD, PhD \\ Gastroenterology and Nutrition, Emma Children's Hospital AMC / \\ Academic Medical Center, Meibergdreef 9, 1105 AZ Amsterdam, \\ The Netherlands. \\ E-mail: m.a.benninga@amc.uva.nl \\ Current Gastroenterology Reports 2007, 9:245-253 \\ Current Medicine Group LLC ISSN 1522-8037 \\ Copyright (C) 2007 by Current Medicine Group LLC
}

In the majority of infants and children with constipation, no obvious cause can be identified. A rare cause of constipation is Hirschsprung disease (HD). HD is characterized by the absence of ganglion cells from the anorectum for a variable length up to the duodenum. The extent of the aganglionic segment varies, but in most patients the lesion does not extend beyond the rectum and sigmoid colon. This review focuses on the passage of meconium, the recognition of HD, and new insights in its pathophysiology and genetics. The authors also provide a summary of the diagnostic evaluation and treatment of HD in infancy and childhood.

\section{Introduction}

In healthy term infants, the passage of meconium occurs in $95 \%$ within 24 hours and in $99 \%$ within 48 hours of birth $[1,2]$. This percentage, however, drops dramatically to $66 \%$ in preterm infants ( $\geq 32$ weeks gestation) and those born with low birth weight $(<2500 \mathrm{~g})$ infants [1,2]. Most likely, this delay simply reflects impaired maturation, but it should alert the clinician as it may be the first sign of a defecation disorder.

Especially in premature infants, delayed maturation of the motor mechanisms of the gut might play a role in delayed passage of meconium. In this fragile group of infants, such delayed passage may cause significant morbidity (intestinal perforation) and even mortality. At first instance, a "wait and see" policy is often used in these infants. However, if these infants develop feeding problems and abdominal distention, enemas, laxatives, or both are given to relieve colonic distention and continued until a normal defecation pattern has been developed. In those infants who do not develop a normal defecation pattern in the following weeks, Hirschsprung disease (HD) should be excluded.

To date, the development of colorectal motility is poorly understood in preterm infants. Some authors suggest that preterm infants may have delayed transit of luminal contents through the colon; however, colonic motility has never been directly assessed in these infants [3-5]. Recently, Kenny et al. [6] demonstrated that delayed passage of meconium may result from a delayed maturation of interstitial cells of Cajal. Interstitial cells of Cajal function as pacemaker cells coordinating the electromechanical activity of the gut $[7,8]$.

Factors other than motility may also contribute to the delay in meconium passage. The meconium of premature infants differs in composition (glycoprotein, saccharides, calcium, copper, iron, and phosphorus), making it more viscous and thus more difficult to be expelled [9].

Delayed passage of meconium may result from the absence of the enteric nervous system, as typically described in HD. This is a developmental disorder of the enteric nervous system characterized by the absence of ganglion cells along a variable portion of the distal intestine starting from the internal anal sphincter. More than $90 \%$ of infants with HD fail to pass meconium within 24 hours after birth.

Finally, delayed passage of meconium might also be the first sign of functional constipation. This is a common disorder, and symptoms vary from a relatively mild short-lived bowel problem to severe chronic constipation with fecal impaction and fecal incontinence $[10 \bullet \bullet, 11 \bullet \bullet]$. The pathophysiology underlying functional constipation is undoubtedly multifactorial and not well understood 


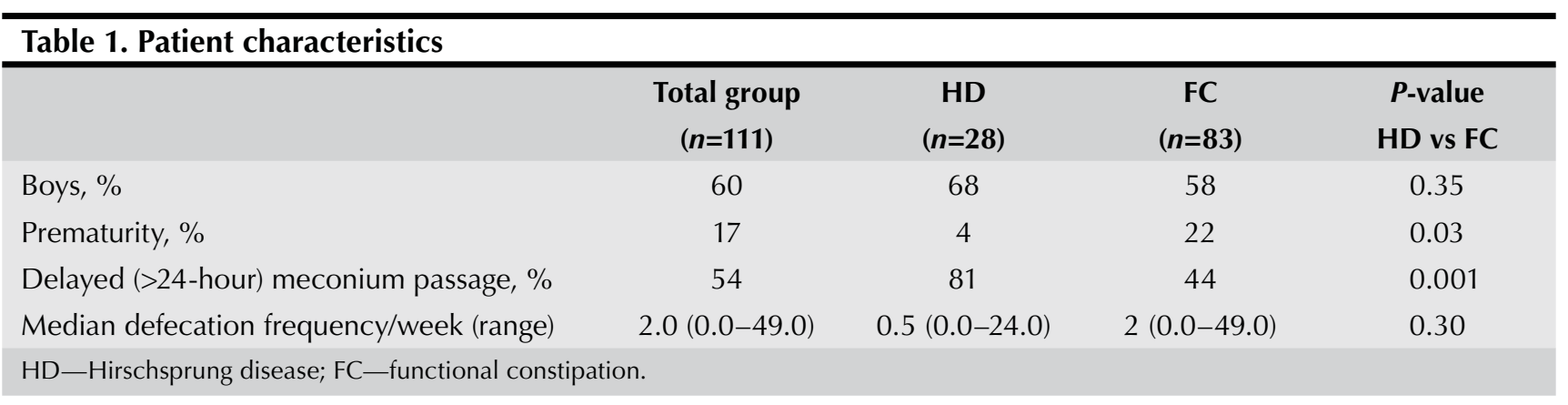

$[10 \bullet \bullet, 11 \bullet \bullet]$. Clearly, functional constipation can result from abnormal function of the regions involved, including the colon, the rectum, and the sphincter complex. No specific organic cause can be found in approximately $90 \%$ of the infants $[11 \bullet \bullet$. We will not discuss functional constipation further in this review. Rather, we focus on the latest findings regarding the pathophysiology, symptomatology, diagnostic evaluation, and treatment of HD in infancy and childhood.

\section{Hirschsprung Disease}

HD is a developmental disorder of the enteric nervous system. It is characterized by the absence of ganglion cells along a variable portion of the distal intestine, which results in functional obstruction caused by dysmotility of the diseased segment, lack of propagation of peristaltic waves into the aganglionic colon, and abnormal or absent relaxation of this segment and of the internal anal sphincter $[12,13]$.

\section{Clinical presentation}

Approximately $80 \%$ to $90 \%$ of all patients with HD have typical clinical symptoms and are diagnosed during the neonatal period. Delayed passage of meconium is the cardinal symptom in neonates with HD. Over $90 \%$ of patients fail to pass meconium within 24 hours after birth [13]. This finding strongly contrasts with results in healthy neonates, who pass meconium within 24 hours in $95 \%$ of the cases. However, in a recent study of 111 infants suspected of having $\mathrm{HD}$, delayed passage of meconium in itself did not seem to be useful as a means to differentiate between HD and functional constipation [14••]. More than $40 \%$ of the children evaluated in this study with functional constipation and approximately $30 \%$ of healthy preterm infants had delayed meconium production (Table 1). In patients presenting with delayed passage of meconium and other important clinical signs, such as vomiting and abdominal distention, however, rapid diagnostic tests are necessary.

The usual presentation of $\mathrm{HD}$ in the neonatal period is constipation, abdominal distention, and vomiting during the first days of life (Table 2). However, about a third of the babies with HD present with diarrhea without obvious distention and vomiting. In these infants, one should be alert because diarrhea in HD is in most cases a symptom of enterocolitis and remains the most common cause of morbidity and mortality in this disease. Adequate therapy is necessary to prevent toxic megacolon, a life-threatening condition characterized by the sudden onset of marked abdominal distention, bile-stained vomiting, fever, and signs of dehydration and shock.

In many cases of $\mathrm{HD}$, a rectal examination brings passage of meconium and relief of the acute intestinal obstruction. These babies may have normal bowel movements for a few days or weeks and then show signs and symptoms of intestinal obstruction. Fecal incontinence, often present in functional constipation in children, is often absent in children with HD (Table 2). However, in a minority of patients, HD may be manifested as chronic constipation with or without abdominal distention and is manageable with changes in diet and laxatives, suppositories, or enemas. Thus, it is clear that early differentiation between HD and functional constipation is necessary to prevent severe complications of HD.

\section{Epidemiology and genetics}

$\mathrm{HD}$ is a rare disorder, and its incidence is estimated to be approximately one in 5000 live births, with a male-to-female ratio of 4 to 1.15 . The majority of children with HD $(93 \%)$ are born at term with a normal birth weight [13].

The length of the affected segment varies and appears to determine the recurrence risk and mode of inheritance. Short-segment or classic HD, involving the rectum and sigmoid, accounts for $75 \%$ to $80 \%$ of cases [15-17]. In the remainder of cases, the aganglionic segment extends more proximally and may even affect the entire colon. In cases of total colonic aganglionosis, a familial incidence of $15 \%$ to $21 \%$ has been reported, increasing up to $50 \%$ in total intestinal aganglionosis [15]. As the length of the aganglionic segment increases, the recurrence risk to siblings increases [18].

Although genetic factors are definitely involved, there is no clear pattern of inheritance, and most investigators have found a sex-modified multifactorial mode of inheritance $[18,19 \bullet \bullet$. So far, ten genes and five loci for HD susceptibility have been identified (Table 3).

Results from many studies indicate that the receptor tyrosine kinase (RET) is the major susceptibility gene for HD [20-22]. Approximately 50 RET mutations 


\begin{tabular}{lll}
\hline Table 2. Presenting symptoms: chronic constipation versus classic Hirschsprung disease \\
\hline Symptoms & Chronic constipation & Hirschsprung disease \\
Fecal incontinence & Common & Rare \\
Abdominal pain & Occasionally & Common \\
Stool size & Large & Normal \\
Failure to thrive & Rare & Common \\
Stool-withholding behavior & Common & Rare \\
Abdominal fecal mass & Common & Rare \\
Ampullary feces & Common & Rare \\
Anorectal examination & Dilated ampulla & Narrow \\
Enterocolitis & Never & Occasionally
\end{tabular}

have been reported in HD patients, accounting for $50 \%$ of familial and $15 \%$ to $20 \%$ of sporadic cases of HD $[18,19 \bullet \bullet . R E T$ mutations are also associated with multiple endocrine neoplasia type 2 (MEN2) and familial medullary thyroid carcinoma $[23,24]$.

In the majority $(70 \%)$, however, HD occurs as an isolated trait (nonsyndromatic HD). Association with chromosomal abnormalities, other birth defects, and syndromes with mendelian patterns of inheritance occurs in $30 \%$ (syndromatic HD). A chromosomal abnormality is associated with HD in $12 \%$ of cases, with trisomy 21 (Down syndrome) by far the most frequent $(>90 \%)$, involving $2 \%$ to $10 \%$ of ascertained HD cases [25]. Associated congenital anomalies are found in $18 \%$ of HD patients and include central nervous system anomalies, genitourinary abnormalities, and other gastrointestinal malformations. Furthermore, HD has been reported in several known syndromes including Smith-Lemli-Opitz syndrome, MEN2, X-linked hydrocephalus, congenital central hypoventilation syndrome, and Waardenburg syndrome type 4 [25].

\section{Etiology and Pathogenesis}

HD is characterized by the absence of ganglion cells in the myenteric (Auerbach) and submucosal (Meissner) plexus of the distal bowel extending proximally from the internal anal sphincter for varying distances. The absence of ganglion cells has been attributed to failure of migration of neural crest cells between the fifth and twelfth week of gestation [26]. The neurons and glia of the enteric nervous system are all derived from precursor cells from the central nervous system primordium. Neural crest cells are produced from the entire length of the neural axis, but only certain tightly defined regions of the neural crest give rise to the enteric nervous system. These precursor cells first migrate from the central nervous system primordium into the oral and anal ends of the intestinal tract early in embryonic life. Subsequently, these cells migrate along the gut to colonize the entire intestine. The enteric nervous system precursor cells dif- ferentiate into a range of neuron types and glial cells and form the complex circuitry necessary for enteric nervous system function $[27,28 \bullet \bullet, 29 \bullet \bullet]$.

HD is regarded as a neurocristopathy, defined as a syndrome or tumor that arises due to an abnormality in neural crest cell development. In HD, the enteric nervous system is inadequately formed due to the arrest of vagal neurocrest cell emigration to the hindgut. The earlier the arrest of migration, the longer the aganglionic segment. Aganglionosis is generally limited to the rectum $(75 \%)$, although in rare cases the aganglionosis may affect the entire colon, the colon and small intestine, or the entire gut [15-17].

The absence of enteric ganglia containing cholinergic neurons, interneurons, and nonadrenergic, noncholinergic neurons is considered the most important pathologic finding in HD. The absence of ganglion cells is accompanied by increased cholinergic and adrenergic nerve fibers because regulation of the development of these nerve fibers is lacking [30]. These abnormalities in innervation explain the inability of the aganglionic segment to relax. The wave of relaxation normally preceding each propulsive contraction does not occur, and furthermore, the rectoanal inhibitory reflex (RAIR) to rectal distention is lacking [30].

\section{RAIR}

The presence of the RAIR is a key factor in the normal defecation process. The RAIR is elicited by distention of the rectal wall, which stimulates mechanoreceptors located in the rectum. This leads to activation of intramural inhibiting neurons, located in the myenteric plexus, relaxing the internal anal sphincter (Fig. 1) [31]. When defecation is not desirable, the external anal sphincter, with the help of the pelvic floor, remains contracted until the rectal wall has adapted to the increased rectal volume.

Results from animal studies have shown that nitric oxide is the main inhibitory neurotransmitter released by these neurons [32]. Blockade of nitric oxide biosynthesis reduced the relaxation of muscle strips of the internal anal sphincter and impaired the RAIR [32,33]. 


\begin{tabular}{|c|c|c|c|c|}
\hline Gene & & Phenotype & Inheritance & Study \\
\hline \multirow[t]{2}{*}{ RET } & $10 q 11.2$ & Nonsyndromatic & Dominant, incomplete penetrance & [67] \\
\hline & Hirschsprung-MEN2A/FMTC & & & \\
\hline GDNF & $5 p 13$ & Nonsyndromatic & Non-mendelian & [68] \\
\hline Neurturin & $19 p 13$ & Nonsyndromatic & Non-mendelian & [69] \\
\hline \multirow[t]{2}{*}{$E D N R B$} & $13 q 22$ & Shah-Waardenburg & Recessive & [70] \\
\hline & & Nonsyndromatic & Dominant (de novo in $80 \%$ ) & \\
\hline \multirow[t]{2}{*}{ EDN3 } & $20 q 13$ & Shah-Waardenburg & Recessive & {$[71]$} \\
\hline & & Nonsyndromatic & Dominant, incomplete penetrance & \\
\hline SOX10 & $22 q 13$ & Shah-Waardenburg & Dominant (de novo in $75 \%$ ) & [72] \\
\hline ECE-1 & $1 \mathrm{p} 36$ & Congenital heart malformation & De novo dominant & {$[73,74]$} \\
\hline ZFHX1B* & $2 q 22$ & Mowat-Wilson & De novo dominant & [75] \\
\hline KIAA1279 & $10 q 21.3-q 22.1$ & Goldberg-Shprintzen & Recessive & [76] \\
\hline$P M X 2 b$ & $4 p 12$ & $\begin{array}{l}\text { Congenital central hypoventilation } \\
\text { syndrome (CCHS) }\end{array}$ & De novo in $90 \%$ & [77] \\
\hline Unknown & $3 p 21$ & Nonsyndromatic, S-HSCR & Non-mendelian & [78] \\
\hline Unknown & $9 q 31$ & Nonsyndromatic, L-HSCR & Dominant, incomplete penetrance & [79] \\
\hline Unknown & $19 q 12$ & Nonsyndromatic, S-HSCR & Non-mendelian & [78] \\
\hline Unknown & $16 q 23$ & Shah-Waardenburg & Non-mendelian & [70] \\
\hline Unknown & $4 q 31.3-q 32.3$ & Nonsyndromatic, S-HSCR & $\begin{array}{l}\text { Autosomal dominant, incomplete } \\
\text { penetrance }\end{array}$ & [80] \\
\hline $\begin{array}{l}\text { *ZFHX1B en } \\
\text { ECE1—endo } \\
\text { carcinoma; } \\
\text { MEN2A-n } \\
\text { SOX10-sex }\end{array}$ & les Smad-interacting protein-1 (S & $\begin{array}{l}\text { AADIP1 or SIP1), and PMX2b, paired me } \\
\text {-endothelin-3; EDNRB-endothelin rece } \\
\text { ropic factor; HD-Hirschsprung disease } \\
\text { RET-rearranged during transfection; S- } \\
\text { box 10; ZFHX1B - zinc finger homeo bo }\end{array}$ & $\begin{array}{l}\text { esoderm homeobox gene. } \\
\text { eptor B; FMTC-familial medullary thyroid } \\
\text { e; L-HSCR-long segment Hirschsprung di } \\
\text { HSCR—-short-segment Hirschsprung disea } \\
\text { x 1B. }\end{array}$ & ease; \\
\hline
\end{tabular}

Recent evidence has shown that the nitrergic innervation is dependent on the presence of an intact network of interstitial cells of Cajal, cells of mesenchymal origin distributed within the tunica muscularis of the gastrointestinal tract $[34,35]$. The interstitial cells of Cajal function as pacemaker cells coordinating the electromechanical activity of the gut $[7,8]$. A second subset of interstitial cells of Cajal located in the muscular layer has been shown to mediate the nitrergic neurotransmission in the stomach and lower esophageal sphincter [34]. Interstitial cells of Cajal have also been shown to play a role in the afferent limb of the RAIR [36].

\section{Diagnosis}

Due to the risk of significant complications of HD, it is clinically important to differentiate infants with HD from infants with functional constipation. Contrast enema, anorectal manometry, and rectal suction biopsy are the most common tests used in the diagnostic work-up of HD. Because the sensitivity and specificity of these tests varies widely [37], the appropriate diagnostic approach for HD is still a matter of debate [38-41]. In most centers, however, the reference standard for diagnosing HD is a full-thickness rectal biopsy. This test provides the most definitive answer, but it is invasive and requires general anesthesia.

\section{Contrast enema}

Contrast enema is one of the first investigations used to evaluate lower intestinal obstruction in infancy and to differentiate HD from other possible diagnoses, such as meconium ileus, distal atresias, and meconium plug syndrome [42]. To imitate the natural situation, it is important to perform a contrast enema in the unprepared colon, without prior enemas or disimpaction [43]. However, even in experienced hands a contrast enema is difficult to evaluate. The classic finding in patients with HD is a caliber change between the small or normal-sized distal aganglionic segment and the dilated proximal ganglionic bowel [44]. In some cases, an abnormal mucosal pattern may be observed, indicating the presence of enterocolitis. However, in young children or in cases of total aganglionosis, the caliber change is more difficult to demonstrate [40,45-47]. On the other hand, rectal enemas and even digital rectal examination may decompress the distended proximal 


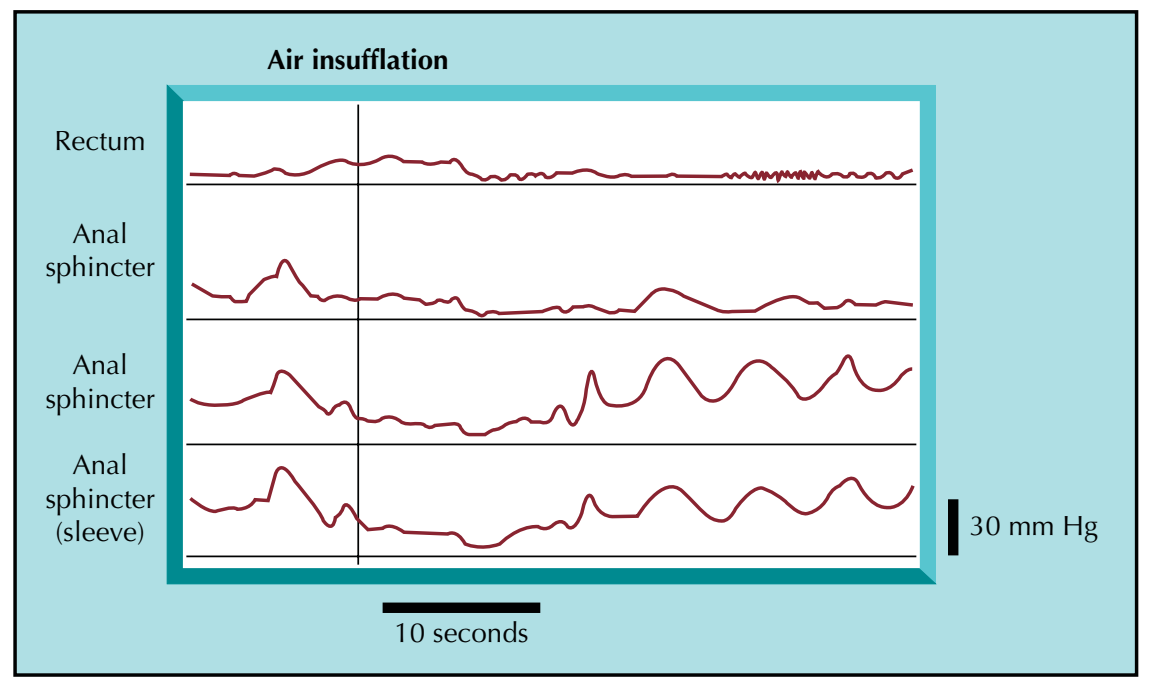

Figure 1. Anorectal pressure recordings in a 29-week-old premature infant showing rectal inhibitory reflex (RAIR) elicited by air insufflation.

bowel with distortion of the caliber change, leading to false-negative test results. Contrast enema might be presumed helpful for the surgeon to assess the localization of the caliber change and thus the length of the aganglionic segment. However, the assessment of length of aganglionosis has often been questioned in the literature [48].

\section{Anorectal manometry}

Anorectal manometry is a relatively safe and noninvasive technique. It measures pressures in the anorectal region and provides a way to quantify the function of the internal and external sphincters. Although this technique is widely used, lack of standardization in methodology (open-tipped perfusion, closed triple-balloon, pressure transducers) has resulted in inconsistent data $[49,50]$.

The main indication to perform this procedure is for demonstration of the presence of the RAIR (Fig. 1). The RAIR can be elicited by rectal balloon distention with small volumes of air $(1-60 \mathrm{~mL})$. Term and premature infants older than 26 weeks in postmenstrual age have a normally developed RAIR to rectal distention $[52,53]$. False-positive test results may ensue from insufficient inflation of the balloon in children with a megarectum, as larger volumes are required in these children to elicit a RAIR [53]. Furthermore, such technical factors as air leak in the circuit or an incorrectly positioned catheter in the sphincter complex can also cause false-positive or negative test results. Artifacts are common in agitated or crying infants, and results should be interpreted with caution.

\section{Histology}

Classically, the diagnosis of HD is based on histochemical evaluation of the rectum. This examination typically shows absence of ganglion cells in the submucous and myenteric plexus and an increase in acetylcholinesterase activity in the parasympathetic nerve fibers of the lamina propria mucosa, muscularis mucosa, and circular muscles
(Fig. 2) [44]. Two methods are used to obtain tissue for histochemical evaluation.

\section{Rectal suction biopsy}

Rectal suction biopsy can be performed with no anesthetic and little risk; several biopsies are taken above the anal margin (at 2 and $4 \mathrm{~cm}$ from the anal margin, anterior and posterior). This technique should reduce the risk of sampling from the normal aganglionic anal canal or of missing an ultra-short segment of HD. The instrument used for biopsies must be sharp to get good-sized specimens. However, because the specimens are small compared with full-thickness specimens, the examination remains difficult even for experienced pathologists [45]. The introduction of staining for acetylcholinesterase activity on a suction biopsy has made the morphologic diagnosis of HD easier and more reliable [44,54]. Possible causes for false-negative test results are sampling error, superficial biopsy material that lacks muscularis mucosa, technical variations in staining technique, and the relative experience of individual pathologists. Furthermore, in neonates a false-negative result may be caused by the immaturity of the submucous plexus [44]. Possible complications of this procedure are perforation, bleeding, and infection.

\section{Full-thickness biopsy}

The classic approach is full-thickness biopsy of rectal mucosa and underlying muscle. However, this method requires general anesthesia and suturing of the biopsy site [55]. As with the suction biopsy, possible complications of this procedure are perforation, bleeding, and infection. Absence of ganglion cells in a full-thickness biopsy confirms the diagnosis of HD.

\section{Sensitivity and specificity of diagnostic tests}

In a recent large prospective study in 111 patients, de Lorijn et al. [14••] showed that rectal suction biopsy had the highest sensitivity (93\%) and specificity (100\%), but 


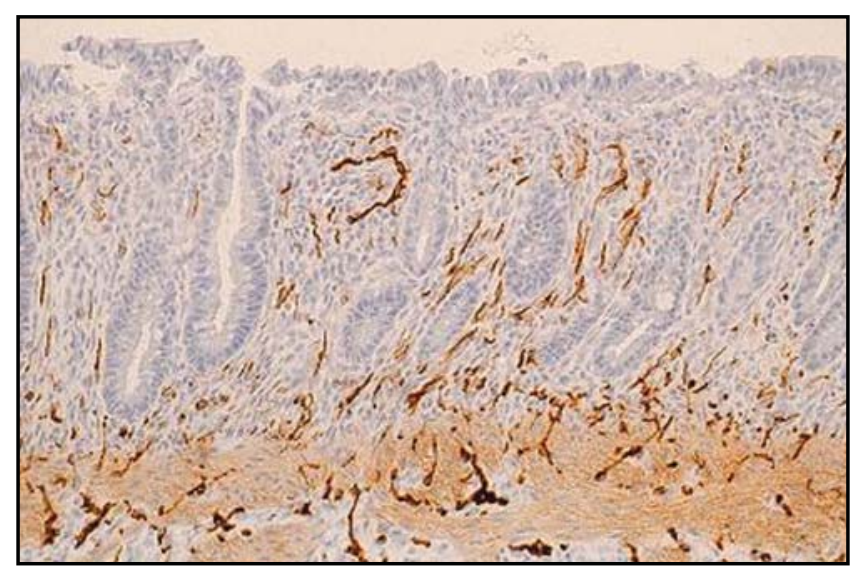

Figure 2. Increased acetylcholinesterase activity in the aganglionic bowel.

values were not significantly different from those in contrast enema (sensitivity $=76 \%, P=0.29$; specificity $=97 \%$, $P=0.50$ ) or from anorectal manometry (sensitivity $=83 \%$, $P=0.69$; specificity $=93 \%, P=0.06$ ). Inconclusive test results occurred in eight infants with contrast enema ( 3 with HD), in 15 infants with anorectal manometry due to agitation (5 with HD), and in two infants with rectal suction biopsy (1 with HD). The authors concluded that rectal suction biopsy is the most accurate test to diagnose Hirschsprung disease, although differences did not reach statistical significance. Moreover, rectal suction biopsy also had the lowest rate of inconclusive test results. In our opinion, the value of a contrast enema in the evaluation of HD is limited because of its fairly low sensitivity and high radiation exposure. Only if the diagnosis of HD has been established, contrast enema may be helpful for the surgeon to assess the localization of the caliber change and thus the length of the aganglionic segment.

\section{Differential diagnosis}

Other causes of intestinal obstruction should be considered when abdominal distention and failure to pass meconium occur in a newborn infant. The following organic disorders are important to exclude: meconium ileus (resulting from cystic fibrosis); intestinal malformations such as lower ileal and colonic atresia or congenital strictures; malrotation (which requires immediate surgery); and functional intestinal obstruction resulting from maternal infection, maternal intoxication, or congenital hypothyroidism. Furthermore, enteric nervous system anomalies, such as hypoganglionosis, hyperganglionosis, intestinal neuronal dysplasia type $\mathrm{B}$, and immaturity of the submucous and myenteric plexus, should be considered. These anomalies lead to chronic intestinal pseudoobstruction and can be differentiated from HD by histologic staining. A full-thickness biopsy is needed to diagnose hyperganglionosis and intestinal neuronal dysplasia type B (giant ganglia), and lactic dehydrogenase reaction is needed to verify the maturity of the ganglia [44].

\section{Treatment}

Once the diagnosis of HD has been confirmed by rectal biopsy, the infant should be prepared for laparotomy. When rectal biopsy is inconclusive, the clinical picture will determine the persistence of repeat biopsy attempts and, if necessary, full-thickness biopsy sampling to confirm the clinically suspected diagnosis of HD. If the newborn has enterocolitis complicating HD, the child will require correction of dehydration and electrolyte imbalance by infusion of appropriate fluids. It is essential to decompress the bowel immediately and permanently. Deflation of the intestine may be carried out initially by rectal irrigations through a cannula. When the baby is clinically stable a colostomy will be performed.

For many years, the vast majority of cases of HD have been diagnosed in the neonatal period [56]. Laparotomy is generally performed between 6 and 12 months of age. The advantages of operating in the first year are that the colonic dilatation can be quickly controlled by washouts and at operation the caliber of the pull-through bowel is nearly normal, allowing for an accurate anastomosis that minimizes leakage and cuff infection [57,58].

A number of different operations have been described for the treatment of HD. Currently, many centers are performing one-stage pull-through procedures in newborn infants with minimal morbidity and encouraging results $[59,60]$.

The basic principle is to bring the ganglionic bowel down to the anus. During surgery, biopsies for frozen sections are taken to determine the level of transition, and a colostomy is placed proximal to the transition zone. The three most commonly used operation techniques are the rectosigmoidectomy developed by Swenson, the retrorectal transanal approach developed by Duhamel, and the endorectal procedure developed by Soave. Recent innovations are the transanal endorectal pull-through and the laparoscopic approach to all three techniques.

A recent long-term study in 41 patients with HD comparing transanal pull-through to transabdominal pull-through showed a significantly better continence outcome for the abdominal approach [59]. However, the stooling pattern and enterocolitis scores were somewhat better for the latter group.

An excellent review by Geerdes et al. [60] provides more detailed information about surgical procedures.

\section{Prognosis after surgery}

Surgical reconstruction for HD provides near-normal gastrointestinal function for the majority of children [61]. In general, the most commonly encountered postoperative problems include constipation (more often with Duhamel technique), incontinence, enterocolitis (more often with Swenson and Soave technique), and the overall impact of the disease on lifestyle [60]. Other complications, such as fistulae and obstructions, are quite rare $[62,63]$.

Although gastrointestinal function improves after surgery, long-term follow-up reveals significant residual 
problems. Unfortunately, most reviews of HD are hampered by short follow-up periods that may not adequately reflect long-term outcome and lifestyle. One of the more complete studies on this subject was performed by Moore et al. [64,65]. These authors described the overall quality of life as quite good, with $94 \%$ of children becoming welladjusted members of society. Although patients had low weight for their age, this generally corrected with time. Additionally, developmental milestones and school performance were satisfactory in most patients $195 \%$ and $82 \%$, respectively). Clearly, patients with poor functional outcome have a greater tendency to have more psychosocial problems. In general, Moore et al. [64,65] were quite positive about quality of life issues in their review of children after an endorectal procedure. Factors that were predictive of poor quality of life were fecal incontinence $(2.5 \%-13.6 \%)$ and poor family report.

Another recently published study showed that patients with HD encountered more "overall" physical health problems compared with healthy subjects, but HD patients did not show additional pain or limitations in functioning due to physical problems [66]. Psychosocial functioning had the most important effect on the quality of life of patients with HD, whereas fecal incontinence and constipation had almost no effect on their quality of life.

\section{Conclusions}

HD is a rare gastrointestinal disorder in which delayed passage of meconium is the key characteristic. Early recognition and adequate therapy are necessary to prevent toxic megacolon. Rectal suction biopsy is the most accurate test to diagnose HD and has the highest sensitivity and specificity. A negative rectal suction biopsy virtually rules out the diagnosis of HD. However, if symptoms of severe constipation persist and clinical suspicion remains high, further evaluation (anorectal manometry and contrast enema) is necessary.

\section{References and Recommended Reading}

Papers of particular interest, published recently, have been highlighted as:

- Of importance

- Of major importance

1. Weaver LT, Lucas A: Development of bowel habit in preterm infants. Arch Dis Child 1993, 68:317-320.

2. Verma A, Dhanireddy R: Time of first stool in extremely low birth weight $(<$ or $=1000$ grams $)$ infants. $J$ Pediatr 1993, 122:62-69.

3. MClain CR Jr: Amniopraphy studies of the gastrointestinal motility of the human fetus. Am J Obstet Gynecol 1963, 86:1079-1087.

4. Dumont RC, Rudolph CD: Development of gastrointestinal motility in the infant and child. Gastroenterol Clin North Am 1994, 23:655-671.

5. Sarna SK: Physiology and pathophysiology of colonic motor activity (2). Dig Dis Sci 1991, 36:998-1018.
6. Kenny SE, Vanderwinden JM, Rintala RJ, et al.: Delayed maturation of the interstitial cells of Cajal: a new diagnosis for transient neonatal pseudoobstruction. Report of two cases. J Pediatr Surg 1998, 33:94-98.

7. Huizinga JD: Physiology and pathophysiology of the interstitial cell of Cajal: from bench to bedside. II. Gastric motility: lessons from mutant mice on slow waves and innervation. Am J Physiol Gastrointest Liver Physiol 2001, 281:G1129-G1134.

8. Huizinga JD, Thuneberg L, Kluppel M, et al.: W/kit gene required for interstitial cells of Cajal and for intestinal pacemaker activity. Nature 1995, 373:347-349.

9. Dimmitt RA,.Moss RL: Meconium diseases in infants with very low birth weight. Semin Pediatr Surg 2000, 9:79-83.

10.• Hyman PE, Milla PJ, Benninga MA, et al.: Childhood functional gastrointestinal disorders: neonate/toddler. Gastroenterology 2006, 130:1519-1526.

A landmark paper on functional gastrointestinal disorders in the neonate and toddler.

11.• Benninga MA, Voskuijl WP, Taminiau JA. Childhood constipation: is there new light in the tunnel? J Pediatr Gastroenterol Nutr 2004, 39:448-464.

Excellent review on symptomatology, pathophysiology, and treatment of childhood constipation.

12. Scharli AF, Kiesewetter WB: Defecation and continence: some new concepts. Dis Colon Rectum 1970, 13:81-107.

13. Puri P: Hirschsprung's disease: clinical generalities. In Hirschsprung's Disease and Allied Disorders. Edited by Holschneider AM, Puri P. Frankfurt, Germany: Springer; 2000:129-135.

14.• de Lorijn F, Reitsma JB, Voskuijl WP, et al.: Diagnosis of Hirschsprung's disease: a prospective, comparative accuracy study of common tests. J Pediatr 2005, 1146:787-792

Report from a large prospective study which showed that RSB had the highest sensitivity and specificity, but values were not significantly different from $\mathrm{CE}$ and from ARM.

15. Badner JA, Sieber WK, Garver KL, Chakravarti A. A genetic study of Hirschsprung's disease. Am J Hum Genet 1990, 46:568-80.

16. Ikeda K, Goto S: Diagnosis and treatment of Hirschsprung's disease in Japan. An analysis of 1628 patients. Ann Surg 1984, 199:400-405.

17. Kleinhaus S, Boley SJ, Sheran M, Sieber WK: Hirschsprung's disease -- a survey of the members of the Surgical Section of the American Academy of Pediatrics. J Pediatr Surg 1979, 14:588-597.

18. Plaza-Menacho I, Burzynski GM, de Groot JW, et al.: Current concepts in RET-related genetics, signaling and therapeutics. Trends Genet 2006, 22:627-36.

19.• Brooks AS, Oostra BA, Hofstra RM: Studying the genetics of Hirschsprung's disease: unraveling an oligogenic disorder. Clin Genet 2005, 67:6-14.

A superb review describing studies involved in the genetics of HD.

20. Edery P, Lyonnet S, Mulligan LM, et al.: Mutations of the RET proto-oncogene in Hirschsprung's disease. Nature 1994, 367:378-380.

21. Romeo G, Ronchetto P, Luo Y, et al.: Point mutations affecting the tyrosine kinase domain of the RET protooncogene in Hirschsprung's disease. Nature 1994, 367:377-378.

22. Iwashita T, Kurokawa K, Qiao S, et al.: Functional analysis of ret with Hirschsprung mutations affecting its kinase domain. Gastroenterology 2001, 121:24-33.

23. Eng C: Seminars in medicine of the Beth Israel Hospital, Boston. The RET proto-oncogene in multiple endocrine neoplasia type 2 and Hirschsprung's disease. N Engl J Med 1996, 335:943-951.

24. Borrello MG, Smith DP, Pasini B, et al.: RET activation by germline MEN2A and MEN2B mutations. Oncogene 1995, 11:2419-2427.

25. Amiel J, Lyonnet S: Hirschsprung's disease, associated syndromes, and genetics: a review. J Med Genet 2001, 38:729-739. 
26. Taraviras S, Pachnis V: Development of the mammalian enteric nervous system. Curr Opin Genet Dev 1999, 9:321-327.

27. Bates MD: Development of the enteric nervous system. Clin Perinatol 2002, 29:97-114.

28.• Gershon MD, Ratcliffe EM: Developmental biology of the enteric nervous system: pathogenesis of Hirschsprung's disease and other congenital dysmotilities. Semin Pediatr Surg 2004, 13:224-235.

A review describing the development of the enteric nervous system.

29.•• Chitkara DK, Di Lorenzo C. From the bench to the 'crib'-side: implications of scientific advances to paediatric neurogastroenterology and motility. Neurogastroenterol Motil 2006, 18:251-262.

An extensive review highlighting advances in pathogenesis and treatment of HD, pseudoobstruction syndrome, and slow transit constipation.

30. Scharli AF: Pathophysiology of Classical Hirschsprung's disease. In Hirschsprung's Disease and Allied Disorders. Edited by Holschneider AM, Puri P. Frankfurt, Germany: Springer; 2000:109-125.

31. Farouk R, Bartolo DC: The anorectum. In An Illustrated Guide to Gastrointestinal Motility. Edited by Kumar D, Wingate D. New York: John Wiley; 1993:449-470.

32. Stebbing JF, Brading AF, Mortensen NJ: Nitric oxide and the rectoanal inhibitory reflex: retrograde neuronal tracing reveals a descending nitrergic rectoanal pathway in a guinea-pig model. Br J Surg 1996, 83:493-498.

33. Rattan S, Chakder S: Role of nitric oxide as a mediator of internal anal sphincter relaxation. Am J Physiol 1992, 262: G107-G12.

34. Ward SM, Morris G, Reese L, et al.: Interstitial cells of Cajal mediate enteric inhibitory neurotransmission in the lower esophageal and pyloric sphincters. Gastroenterology 1998, 115:314-329.

35. Burns AJ, Lomax AE, Torihashi S, et al.: Interstitial cells of Cajal mediate inhibitory neurotransmission in the stomach. Proc Natl Acad Sci U S A 1996, 93:1200-1213.

36. de Lorijn F, de Jonge WJ, Wedel T, et al.: Interstitial cells of cajal are involved in the rectoanal inhibitory. Gut 2005, 54:1107-1113

37. de Lorijn F, Kremer LC, Reitsma JB, Benninga MA: Diagnostic tests in Hirschsprung's disease: a systematic review. $J$ Pediatr Gastroenterol Nutr 2006, 42:496-505.

38. Emir H, Akman M, Sarimurat N, et al.: Anorectal manometry during the neonatal period: its specificity in the diagnosis of Hirschsprung's disease. Eur J Pediatr Surg 1999, 9:101-103.

39. Osatakul S, Patrapinyokul S, Osatakul N: The diagnostic value of anorectal manometry as a screening test for Hirschsprung's disease. J Med Assoc Thai 1999, 82:1100-1105.

40. De Campo JF, Mayne V, Boldt DW, De Campo M: Radiological findings in total aganglionosis coli. Pediatr Radiol 1984, 14:205-209.

41. Athow AC, Filipe MI, Drake DP: Problems and advantages of acetylcholinesterase histochemistry of rectal suction biopsies in the diagnosis of Hirschsprung's disease. J Pediatr Surg 1990, 25:520-526.

42. Smith SD, Tagge EP, Hannakan C, Rowe MI: Characterization of neonatal multisystem organ failure in the surgical newborn. J Pediatr Surg 1991, 26:494-497.

43. Seth R, Heyman MB: Management of constipation and encopresis in infants and children. Gastroenterol Clin North Am 1994, 23:621-636.

44. Blake NS: Diagnosis of Hirschsprung's disease and allied disorders. In Hirschsprung's Disease and Allied Disorders. Edited by Holschneider AM, Puri P. Frankfurt, Germany: Springer; 2000:223-290.

45. Doig CM: Hirschsprung's disease: a review. Int J Colorectal Dis 1991, 6:52-62.

46. Taxman TL, Yulish BS, Rothstein FC: How useful is the barium enema in the diagnosis of infantile Hirschsprung's disease? Am J Dis Child 1986, 140:881-884.
47. Das NL, Hingsbergen EA: Case 22: total colonic aganglionosis--long-segment Hirschsprung disease. Radiology 2000, 215:391-394.

48. Proctor ML, Traubici J, Langer JC, et al.: Correlation between radiographic transition zone and level of aganglionosis in Hirschsprung's disease: Implications for surgical approach. J Pediatr Surg 2003, 38:775-778.

49. Benninga MA: Constipation and faecal incontinence in childhood [thesis]. Baarn: Bosch en Keuning; 1994.

50. Nurko S: Gastrointestinal manometry, methodology and indications. In Pediatric Gastrointestinal Disease. Edited by Walker W, Durie PR, Hamilton JR, et al.: Philadelphia: BC Decker; 2000:1485-1510.

51. Benninga MA, Omari TI, Haslam RR, et al.: Characterization of anorectal pressure and the anorectal inhibitory reflex in healthy preterm and term infants. J Pediatr 2001, 139:233-237.

52. de Lorijn F, Omari TI, Kok JH, et al.: Maturation of the rectoanal inhibitory reflex in very premature infants. J Pediatr 2003, 143:630-633.

53. Meunier P, Marechal JM, de Beaujeu MJ: Rectoanal pressures and rectal sensitivity studies in chronic childhood constipation. Gastroenterology 1979, 77:330-336.

54. Meier-Ruge W, Lutterbeck PM, Herzog B, et al.: Acetylcholinesterase activity in suction biopsies of the rectum in the diagnosis of Hirschsprung's disease. J Pediatr Sur 1972, 7:11-17.

55. Kurer MH, Lawson JO, Pambakian H: Suction biopsy in Hirschsprung's disease. Arch Dis Child 1986, 61:83-84.

56. Ghosh A, Griffiths DM: Rectal biopsy in the investigation of constipation. Arch Dis Child 1998, 79:266-268.

57. Sherman JO, Snyder ME, Weitzman JJ, et al.: A 40-year multinational retrospective study of 880 Swenson procedures. J Pediatr Surg 1989, 24:833-838.

58. Georgeson KE, Fuenfer MM, Hardin WD: Primary laparoscopic pull-through for Hirschsprung's disease in infants and children. J Pediatr Surg 1995, 30:1017-1021.

59. El-Sawaf MI, Drongowski RA, Chamberlain JN, et al.: Are the long-term results of the transanal pull-through equal to those of the transabdominal pull-through? A comparison of the 2 approaches for Hirschsprung disease. J Pediatr Surg 2007, 42:41-47

60. Geerdes BP, Hazebroek FWJ: Pediatric disorders of the distal gastrointestinal tract, surgical aspects. In Integrated Medical and Surgical Gastroenterology. Edited by Lanschot JJB, Gouma DJ, Jansen PLM, et al.: Stuttgart, Germany: Thieme Medical Publishers; 2004:644-653.

61. Marty TL, Seo T, Matlak ME, et al.: Gastrointestinal function after surgical correction of Hirschsprung's disease: long-term follow-up in 135 patients. J Pediatr Surg 1995, 30:655-658.

62. Teitelbaum DH, Caniano DA, Qualman SJ: The pathophysiology of Hirschsprung's-associated enterocolitis: importance of histologic correlates. J Pediatr Surg 1989, 24:1271-1277.

63. Puri P, Wester T: Enterocolitis complicating Hirschsprung's Disease. In Hirschsprung's Disease and Allied Disorders. Edited by Holschneider AM, Puri P. Frankfurt, Germany: Springer; 2000;165-173.

64. Moore SW, Albertyn R, Cywes S: Clinical outcome and long-term quality of life after surgical correction of Hirschsprung's disease. J Pediatr Surg 1996, 31:1496-1502.

65. Moore SW, Millar AJ, Cywes S: Long-term clinical, manometric, and histological evaluation of obstructive symptoms in the postoperative Hirschsprung's patient. J Pediatr Surg 1994, 29:106-111.

66. Hartman EE, Oort FJ, Aronson DC, et al.: Critical factors affecting quality of life of adult patients with anorectal malformations or Hirschsprung's disease. Am J Gastroenterol 2004, 99:907-913.

67. Attie T, Pelet A, Edery P, et al.: Diversity of RET protooncogene mutations in familial and sporadic Hirschsprung disease. Hum Mol Genet 1995, 4:1381-1386. 
68. Ivanchuk SM, Myers SM, Eng C, Mulligan LM: De novo mutation of GDNF, ligand for the RET/GDNFR-alpha receptor complex, in Hirschsprung's disease. Hum Mol Genet 1996, 5:2023-2026.

69. Doray B, Salomon R, Amiel J, et al.: Mutation of the RET ligand, neurturin, supports multigenic inheritance in Hirschsprung disease. Hum Mol Genet 1998, 7:1449-1452.

70. Carrasquillo MM, McCallion AS, Puffenberger EG, et al.: Genome-wide association study and mouse model identify interaction between RET and EDNRB pathways in Hirschsprung disease. Nat Genet 2002, 32:237-244.

71. Bidaud C, Salomon R, Van Camp G, et al.: Endothelin-3 gene mutations in isolated and syndromic Hirschsprung disease. Eur J Hum Genet 1997, 5:247-251.

72. Pingault V, Bondurand N, Kuhlbrodt K, et al.: SOX10 mutations in patients with Waardenburg-Hirschsprung disease. Nat Genet 1998, 18:171-173.

73. Hofstra RM, Valdenaire O, Arch E, et al.: A loss-of-function mutation in the endothelin-converting enzyme 1 (ECE-1) associated with Hirschsprung disease, cardiac defects, and autonomic dysfunction. Am J Hum Genet 1999, 64:304-308.

74. Wakamatsu N, Yamada Y, Yamada K, et al.: Mutations in SIP1, encoding Smad interacting protein-1, cause a form of Hirschsprung disease. Nat Genet 2001, 27:369-370.
75. Dastot-Le Moal F, Wilson M, et al.: ZFHX1B mutations in patients with Mowat-Wilson syndrome. Hum Mutat 2007 28:313-321.

76. Brooks AS, Bertoli-Avella AM, Burzynski GM, et al.: Homozygous nonsense mutations in KIAA1279 are associated with malformations of the central and enteric nervous systems. Am J Hum Genet 2005, 77:120-126.

77. Amiel J, Laudier B, Attie-Bitach T, et al.: Polyalanine expansion and frameshift mutations of the paired-like homeobox gene PHOX2B in congenital central hypoventilation syndrome. Nat Genet 2003, 33:459-461.

78. Gabriel SB, Salomon R, Pelet A, et al.: Segregation at three loci explains familial and population risk in Hirschsprung disease. Nat Genet 2002, 31:89-93.

79. Bolk S, Pelet A, Hofstra RM, Angrist M, et al.: A human model for multigenic inheritance: phenotypic expression in Hirschsprung disease requires both the RET gene and a new 9q31 locus. Proc Natl Acad Sci U S A, 2004, 97:268-273.

80. Brooks AS, Leegwater PA, Burzynski GM, et al.: A novel susceptibility locus for Hirschsprung's disease maps to 4q31.3-q32.3. J Med Genet 2006, 43:e35. 